\title{
Clinical Decision Analysis of First-line Regimens for Advanced Recurrent Renal Cell Carcinoma
}

\author{
Toshihiro Shida*1, Yuji Endo ${ }^{1}$, Tomoyuki Kato ${ }^{2}$, Norihiko Tsuchiya ${ }^{2}$, \\ Tadashi Shiraishi ${ }^{1}$, Toshinori Ito $^{3}$ and Tadao Inoue ${ }^{3}$ \\ Division of Pharmacy, Yamagata University Hospital ${ }^{1}$, \\ Department of Urology, Faculty of Medicine, Yamagata University ${ }^{2}$, \\ Department of Pharmacy, Ohu University ${ }^{3}$ \\ $\left[\begin{array}{l}\text { Received February 15, } 2017 \\ \text { Accepted March 22, 2017 }\end{array}\right]$
}

Sunitinib and sorafenib as well as interferon- $\alpha$ (IFN- $\alpha$ ) are first-line therapies for advanced or recurrent renal cell carcinoma. Although the efficacy of molecular targeted drugs appears indisputable, some research suggests that they are not significantly effective compared to cytokine therapies in terms of progression-free survival. The therapeutic effects of new drugs depend on the decision of doctors and hospitals, which is partially based on the evaluation of costeffectiveness of these therapies. The purpose of this study was to analyze the clinical decisions involved in selecting IFN- $\alpha$, sunitinib, and sorafenib regimens and to identify the best regimen for the first-line treatment of advanced or recurrent renal cell carcinoma based on clinical and economic evidence.

The health outcomes of the therapies considered in this study were analyzed based on the literature on randomized controlled clinical trials of the drugs. The total costs of the regimens were calculated on the basis of direct costs obtained from medical records of patients diagnosed with advanced or recurrent renal cell carcinoma at Yamagata University Hospital. Cost-effectiveness was analyzed by the Markov chain Monte Carlo (MCMC) method. The study was designed from a social viewpoint.

The MCMC analysis revealed that the incremental cost per effectiveness ratios of sunitinib and sorafenib to IFN- $\alpha$ were 746,919 yen and 421,930 yen per life month, respectively. Molecular targeted drugs are superior to IFN- $\alpha$ in terms of health outcomes but are less cost-effective.

Key words — sunitinib, sorafenib, Markov chain Monte Carlo method, incremental cost per effectiveness ratios (ICER), quality-adjusted life year (QALY)

\section{Introduction}

Renal cell carcinoma patients are estimated to account for $1-2 \%$ of all adult carcinoma patients and $20-30 \%$ of them have metastases at diagnosis. ${ }^{1)}$ Cytokines such as interferon- $\alpha$ (IFN- $\left.\alpha\right)$ or interleukin-2 were the primary treatment options for metastatic renal cell carcinoma. However, they had limited efficacy and the median overall survival (OS) after metastasis diagnosis was approximately 1 year. ${ }^{2)}$ In 2008, sunitinib and sorafenib were approved in Japan and since then, molecular targeted drugs have been used in stan- dard regimens for metastatic renal cell carcinoma. These drugs have improved prognostic outcomes and prolonged the median OS to approximately 3 years., ${ }^{3,4)}$ Sunitinib and sorafenib are receptor tyrosine kinase inhibitors and affect vascular endothelial growth factor receptors. Both are approved in Japan as first-line treatment drugs for advanced or recurrent renal cell carcinoma. However, some research suggests that there is no significant difference in the progression-free survival (PFS) between cytokine therapies and molecular targeted therapies. ${ }^{5)}$ The therapeutic effects of new drugs depend on the decision of doctors and hospitals,

* 2-2-2, Iida-Nishi, Yamagata-shi, Yamagata 990-9585, Japan 
which is partly based on the evaluation of costeffectiveness of these therapies.

As the population ages and fewer babies are born, Japanese national medical expenditure has been growing year by year and it has reached 40 trillion yen in 2013. Increasing medical expenditure is one of the most serious concerns in the country. Reducing medical costs, particularly the supply costs, is important. Although few reports have been published on the cost-effectiveness of chemotherapy drugs used in Japan, pharmacoeconomic analysis of these drugs is necessary to evaluate the therapeutic benefits of molecular targeted drugs. Considering that these new drugs are expensive, the supply cost is one of the major factors to be considered while comparing the efficacy of chemotherapies.

The present study was performed to analyze the clinical decisions involved in selecting IFN- $\alpha$, sunitinib, and sorafenib therapies and to identify the best regimen for the first-line treatment of advanced or recurrent renal cell carcinoma based on clinical and economic evidence.

\section{Methods}

\section{Analysis model}

This is a retrospective observational study from a social viewpoint. A state transition model (a Markov model) was developed to describe the clinical courses in the treatment of advanced or recurrent renal cell carcinoma (Fig 1). The transition model represents three health states: alive without progression (progress-free), alive with progression or relapse (post-progress), and dead (death). We simulated the expected costs resulting

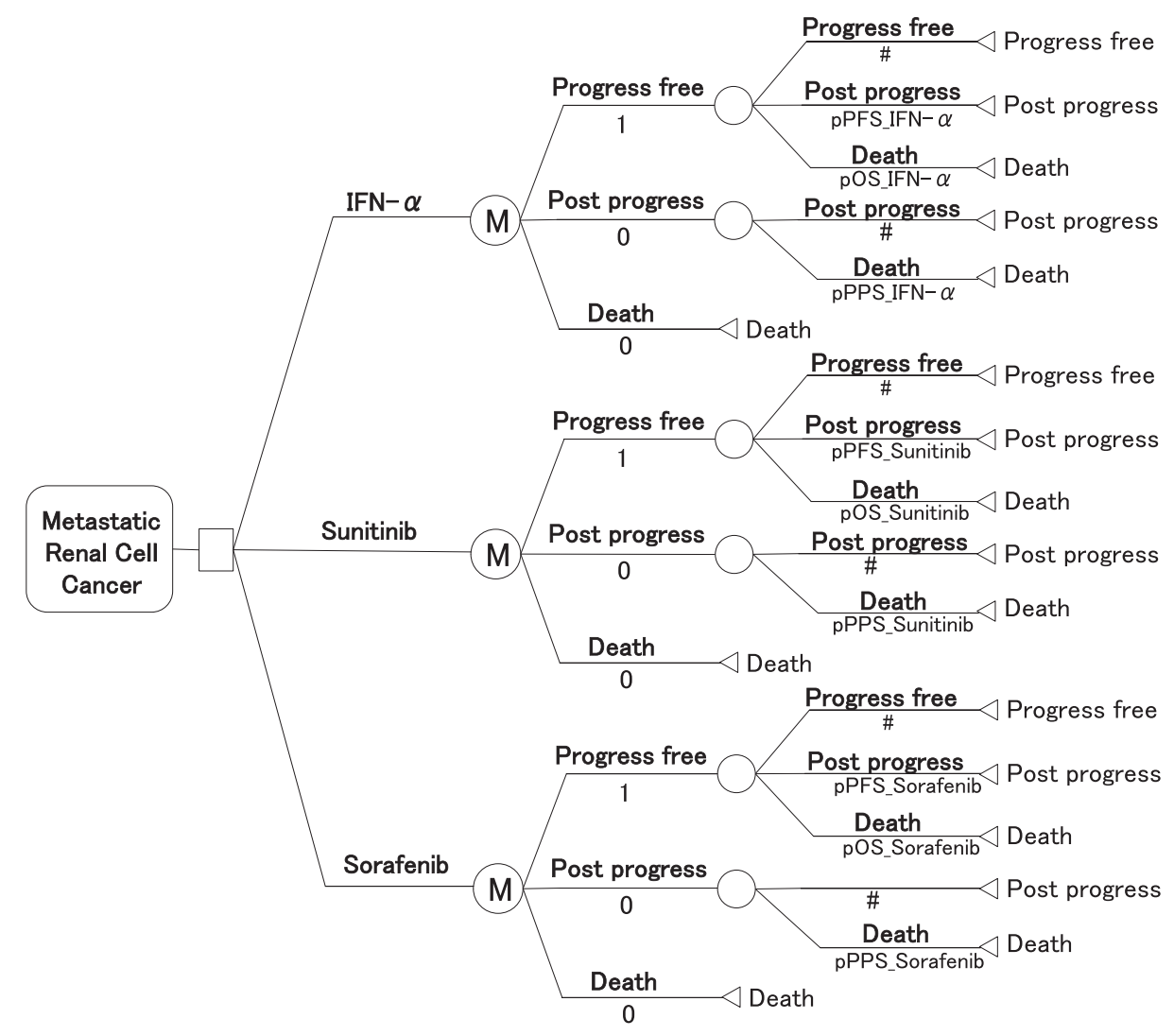

Fig 1 State transition model (a Markov model) of clinical courses in treatment of advanced or recurrent renal cell carcinoma $\square$ : Decision Node; Regimen options, M: Markov Node; Markov process in each regimen, $\bigcirc$ : Chance Node; Probability branch point, $\triangle$ : Terminal Node; Terminal point 
from the treatment of non-resectable advanced renal cancer over a period of 100 months using a hypothetical Markov model.

\section{Target patients}

We evaluated the clinical decisions taken for patients newly diagnosed with advanced or recurrent renal cell carcinoma at the Department of Urology, Yamagata University Hospital between January 1, 2013 and December 31, 2015 and who followed a regimen involving IFN- $\alpha$, sunitinib, or sorafenib as the primary treatment. IFN- $\alpha$ was injected subcutaneously every other day, thrice a week. The dose was 300 IU on week 1, 600 IU on week 2, and $900 \mathrm{IU}$ on week 3-6. Each cycle was 42 days long. Sorafenib was administered continuously for 42 days. Sunitinib was orally administered for 28 days with a 14-day washout period.

\section{Evaluation of health outcomes}

Based on the results of randomized controlled clinical trials of IFN- $\alpha$, sunitinib, and sorafenib treatments for advanced or recurrent renal cell carcinoma, health outcomes (OS and PFS) were evaluated $^{6-11)}$ and the transition probabilities between the three health states in Markov model were calculated.

\section{Resource use and costs}

Medical records and receipts were used to examine the usage of drugs (including drugs used for adverse effects prevention), tests, and medical supplies. The costs of the regimens were calculated on the basis of direct costs, which included drug acquisition, test, medical supply, and personnel costs. The costs were estimated according to the standard dosage of the drugs and the drug acquisition costs were based on the Japanese drug price standard 2014. The costs of tests were computed based on the medical remuneration points revised in 2014.

\section{Evaluation of cost-effectiveness}

We used the life months gained as health outcome and calculated cost per effectiveness ratios (CER) and incremental cost per effectiveness ratios (ICER):

ICER=

CER of a molecular targeted drug - CER of IFN- $\alpha$

Expected life time of a molecular targeted drug - expected life time of IFN- $\alpha$

\section{Ethical consideration}

The protocol of this study was reviewed and approved by Yamagata University Hospital Ethics Committee before the study was begun (No 196). The present study was conducted in compliance with "Ethical Guidelines for Medical and Health Research Involving Human Subjects (enacted on December 22, 2008)" by the Ministry of Health, Labour and Welfare, Japan.

\section{Results}

\section{Health outcomes}

Table 1 shows the reported PFS and OS of the three regimens and Table 2 shows the transition probabilities between health states. Median PFS of IFN- $\alpha$, sunitinib, and sorafenib was 5.3 months (3.9-6.7), 11.6 months (9.4-30.9), and 7.1 months (5.7-8.4) respectively, while median OS was 21.8 months (17.9-26.9), 29.8 months (18.932.9), and 23.1 months (19.9-23.2), respectively. The transition probability from progress-free to post-progress was $12.26 \%$ for IFN- $\alpha, 5.80 \%$ for sunitinib, and $9.30 \%$ for sorafenib and that from post-progress to death was $3.13 \%, 2.30 \%$, and $2.96 \%$, respectively. 
Table 1 Health outcomes of sunitinib, sorafenib and IFN- $\alpha$ regimens

\begin{tabular}{|c|c|c|c|c|c|c|}
\hline \multirow{2}{*}{$\begin{array}{c}\text { Reference } \\
\text { No }\end{array}$} & \multirow{2}{*}{$\begin{array}{c}\text { PFS } \\
\text { Median } \\
\text { (month) }\end{array}$} & \multicolumn{2}{|c|}{$95 \% \mathrm{CI}$} & \multirow{2}{*}{$\begin{array}{c}\text { OS } \\
\text { Median } \\
\text { (month) }\end{array}$} & \multicolumn{2}{|c|}{$95 \% \mathrm{CI}$} \\
\hline & & Min & Max & & Min & $\operatorname{Max}$ \\
\hline \multicolumn{7}{|l|}{ Sunitinib } \\
\hline 6) & 11.0 & 11.0 & 13.0 & 26.4 & 23.0 & 32.9 \\
\hline 7) & 12.2 & 7.8 & 48.8 & 33.1 & 14.8 & not reached \\
\hline \multicolumn{7}{|l|}{ Sorafenib } \\
\hline 8) & - & - & - & 16.9 & 10.5 & 23.2 \\
\hline 9) & 5.7 & 5.0 & 7.4 & - & - & - \\
\hline 10) & 9.1 & 7.3 & 9.5 & 29.3 & 29.3 & not reached \\
\hline 11) & 6.5 & 4.7 & 8.3 & - & - & - \\
\hline \multicolumn{7}{|l|}{ IFN- $\alpha$} \\
\hline 6) & 5.0 & 4.0 & 6.0 & 21.8 & 17.9 & 26.9 \\
\hline 9) & 5.6 & 3.7 & 7.4 & - & - & - \\
\hline
\end{tabular}

IFN: interferon, PFS: progression-free survival, OS: overall survival, $95 \% \mathrm{CI}$ : $95 \%$ confidence interval.

Table 2 Transition probabilities between health states

\begin{tabular}{lcrrrc}
\hline \hline & Probability & $\begin{array}{c}\text { Median } \\
\text { (month) }\end{array}$ & Low & Up & $\begin{array}{c}\text { Monthly } \\
\text { probability }\end{array}$ \\
\hline PFS & & & & & \\
$\quad$ IFN- $\alpha$ & $50 \%$ & 5.3 & 3.9 & 6.7 & 0.123 \\
Sunitinib & $50 \%$ & 11.6 & 9.4 & 30.9 & 0.058 \\
Sorafenib & $50 \%$ & 7.1 & 5.7 & 8.4 & 0.093 \\
OS & & & & & \\
IFN- $\alpha$ & $50 \%$ & 16.5 & 14.0 & 20.2 & 0.041 \\
Sunitinib & $50 \%$ & 18.2 & 9.5 & 2.0 & 0.038 \\
Sorafenib & $50 \%$ & 22.2 & 14.2 & 14.8 & 0.031 \\
PPS & & & & & \\
IFN- $\alpha$ & $50 \%$ & 21.8 & 17.9 & 26.9 & 0.031 \\
Sunitinib & $50 \%$ & 29.8 & 18.9 & 32.9 & 0.023 \\
Sorafenib & $50 \%$ & 23.1 & 19.9 & 23.2 & 0.030 \\
\hline
\end{tabular}

IFN: interferon, PFS: progression-free survival, OS: overall survival, PPS: post progression survival, 95\% CI: $95 \%$ confidence interval.

\section{Costs}

Tables 3 and 4 show backgrounds of target patients and the drug acquisition and test costs, respectively. Most of the target patients were clear cell cancer. The proportion of acquisition costs of molecular targeted drugs was larger than that of IFN- $\alpha$; the test and medical supply costs were also higher for the molecular targeted drug regimens. There was negligible difference in costs between sunitinib and sorafenib.

\section{Cost-effectiveness}

Figure 2 illustrates the simulated curves for probable health states of the target patients. According to the base case analysis, the acquisition costs of IFN- $\alpha$, sunitinib, and sorafenib were $1,426,770$ yen, $6,655,200$ yen, and 4,380,278 yen per month, respectively. The life months gained were 22 months, 29 months, and 29 months, respectively. Markov chain Monte Carlo analysis revealed that ICER of sunitinib and sorafenib to IFN- $\alpha$ were 746,919 yen and 421,930 yen per life month, respectively (Table 5).

\section{Discussion}

Since the approval of sunitinib and sorafenib in 
Table 3 Charactaristics and clinical parameter of patients

\begin{tabular}{|c|c|c|c|c|}
\hline & IFN- $\alpha$ & Sunitinib & Sorafenib & $P$ \\
\hline Number of patients & 4 & 10 & 4 & \\
\hline \multicolumn{5}{|l|}{ Sex } \\
\hline Male & 2 & 8 & 3 & \multirow{2}{*}{$0.26^{\mathrm{a})}$} \\
\hline Fimale & 2 & 2 & 1 & \\
\hline Age (median, range) & $78.5(62-85)$ & $62(38-69)$ & $61(48-77)$ & $0.06^{\mathrm{b})}$ \\
\hline Body weight & $69.6(39.6-72.0)$ & $60.8(38.0-76.5)$ & $56.1(44.6-74.9)$ & $0.99^{b)}$ \\
\hline \multicolumn{5}{|l|}{ Histological type } \\
\hline clear cell & 4 & 8 & 3 & \\
\hline papillary & 0 & 2 & 0 & \\
\hline spindle cell & 0 & 0 & 1 & \\
\hline \multicolumn{5}{|l|}{ ECOG performance status } \\
\hline 0 & 2 & 8 & 2 & \\
\hline 1 & 0 & 2 & 2 & \\
\hline 2 & 2 & 0 & 0 & \\
\hline \multicolumn{5}{|l|}{ Site of metastasis } \\
\hline lung & 4 & 4 & 3 & \\
\hline lymph node & 1 & 5 & 2 & \\
\hline liver & 0 & 2 & 1 & \\
\hline peritoneum & 1 & 0 & 0 & \\
\hline bone & 0 & 4 & 1 & \\
\hline adrenal gland & 0 & 1 & 1 & \\
\hline \multicolumn{5}{|l|}{ Anamnesis } \\
\hline hypertension & 3 & 7 & 1 & \\
\hline hyperlipidemia & 0 & 3 & 0 & \\
\hline hyperglycemia & 1 & 1 & 0 & \\
\hline hyperuricemia & 0 & 2 & 1 & \\
\hline cerebrovascular diseases & 2 & 0 & 1 & \\
\hline asthma & 0 & 1 & 0 & \\
\hline chronic gastritis & 0 & 1 & 0 & \\
\hline
\end{tabular}

a) $\chi^{2}$-test, b) one-way ANOVA. IFN: interferon, ECOG: Eastern Cooperative Oncology Group.

Table 4 Drug acquisition and test costs

\begin{tabular}{lcccc}
\hline \hline & Drug Cost (\%) & Other Drugs & Examination Cost & Total Cost \\
\hline IFN- $\alpha$ & $284,550(86.71)$ & 463 & 43,150 & 328,163 \\
Sunitinib & $838,040(90.99)$ & 3,162 & 79,867 & 921,069 \\
Sorafenib & $785,820(90.34)$ & 3,110 & 80,925 & 869,855 \\
\hline
\end{tabular}

IFN: interferon, Other Drugs: drugs used for adverce effects prevention.

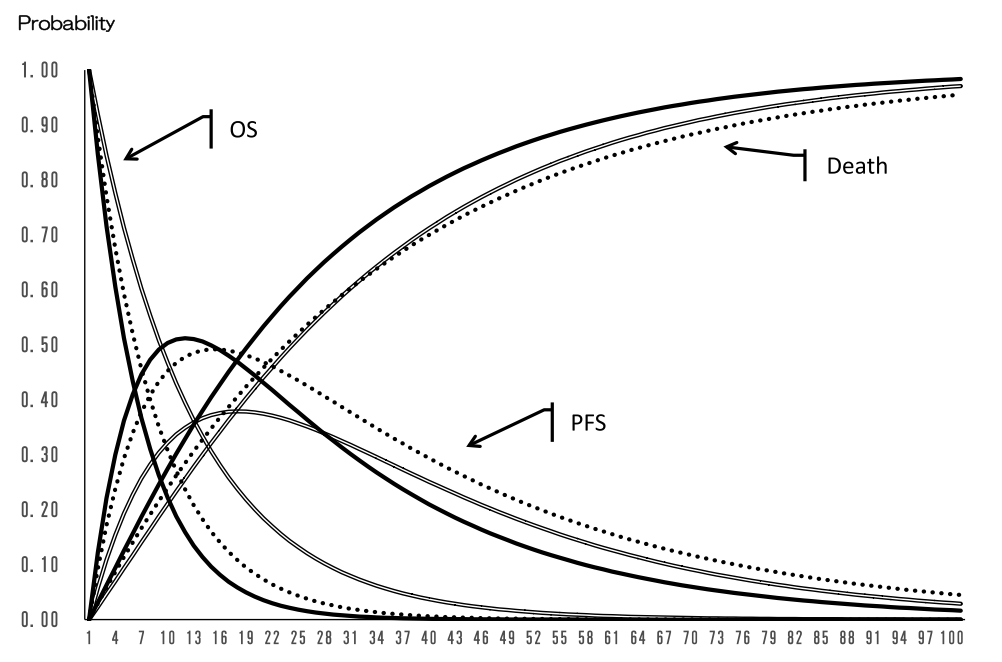

Fig 2 Simulated curves for probable health states

Month

The simulated curves represent three health states: alive without progression (progress-free), alive with progression or relapse (post-progress), and dead (death). - IFN- $\alpha,=$ sunitinib, $\cdots$ sorafenib. 
Table 5 Cost-effectiveness of sunitinib, sorafenib and IFN- $\alpha$ regimens

\begin{tabular}{lcccc}
\hline \hline \multicolumn{1}{c}{ Regimen } & $\begin{array}{c}\text { Effectiveness } \\
\text { (month) }\end{array}$ & $\begin{array}{c}\text { Drug acquisition cost } \\
(¥)\end{array}$ & CER & ICER \\
\hline IFN- $\alpha$ & 22 & $1,426,770$ & 64,853 & - \\
Sunitinib & 29 & $6,655,200$ & 229,490 & $\mathbf{7 4 6 , 9 1 9}$ \\
Sorafenib & 29 & $4,380,278$ & 151,044 & $\mathbf{4 2 1 , 9 3 0}$ \\
\hline
\end{tabular}

IFN: interferon, CER: cost per effectiveness ratio, ICER: incremental cost per effectiveness ratio.

2008, molecular targeted drugs have been standard chemotherapy regimens for metastatic renal cell carcinoma. However, as they are more expensive than the older drugs such as IFN- $\alpha$, their cost-effectiveness and health outcomes should be considered while comparing the efficacy of regimens. In this study, we developed a state transition model (a Markov model) to describe the clinical courses for patients with advanced or recurrent renal cell carcinoma and analyzed the health outcomes and cost-effectiveness of the new and old therapies.

ICER of sunitinib and sorafenib to IFN- $\alpha$ were 746,919 yen and 421,930 yen per life month, respectively. It is stated that the ICER should be within 20,000-30,000 pounds per quality-adjusted life year (QALY) ${ }^{12)}$ in the United Kingdom, and it should be within 50,000-100,000 dollars per QALY in the United States. ${ }^{13)}$ Although there are no clear standards defined in Japan, Shiroiwa et $a l^{14)}$ reports that it is 5 million yen per qualitative adjustment year. It means 416,666 yen per month, and the ICER of the molecular targeted drug therapies considered in this study exceed this criterion. Sunitinib and sorafenib regimens have better health outcomes than the IFN- $\alpha$ regimen do, however, they are less cost-effective. These results can be applied to a broad range of cases as the costs were estimated according to the standard dosage. Other drug expenses and test costs of the molecular targeted drug regimens were also higher than those for the IFN- $\alpha$ regimen were, and the countermeasures against ad- verse effects involved several expenses. Our results indicate that molecular targeted drugs are less cost-effective compared to IFN- $\alpha$ and not suitable as first-line treatment.

Sorafenib and sunitinib had similar expected life times, but ICER of the former was 324,989 yen lower than that of the latter. Although sorafenib is only recommended as the second-line therapy after failure of cytokine therapy ${ }^{15)}$ and is selected in a clinical setting when it is inevitable to use molecular targeted drugs, sorafenib is more cost-effective than sunitinib is. The US National Comprehensive Cancer Network Guidelines recommend that, for clear cell renal carcinoma, sorafenib should be used for carefully selected patients (https://www.tri-kobe.org/nccn/guideline/ urological/english/kidney.pdf, March 7, 2017), but some reports suggest that it is effective for papillary renal cell carcinoma. ${ }^{16,17)}$ Therefore, histological types should be taken into account in evaluating cost-effectiveness.

The present study was designed from a social viewpoint. Molecular targeted drugs have contributed to the remarkable improvement in the prognostic outcomes of renal cell carcinoma treatments. This implies a higher PFS and, thus, the notion of ICER has become more important because considering the patients' quality of life is essential in the evaluation of regimens.

\section{Conflict of Interest}

We have no financial relationships to disclose. 


\section{References}

1) Börje L, Damian CH, Marcus AK, Axel SM, Peter FM, Jean-Jacques P, Ioanel CS, Renal Cell Carcinoma Guideline, European Urology, 2007, 51,1502-1510.

2) Parton M, Gore M, Eisen T, Role of cytokine therapy in 2006 and beyond for metastatic renal cell cancer, J Clin Oncol, 2006, 24, 5584-5592.

3) Figlin R, Sternberg C, Wood CG, Novel agents and approaches for advanced renal cell carcinoma, $J$ Urol, 2012, 188, 707-715.

4) Miyazaki A, Miyake H, Harada K, Inoue T, Fujisawa M, Prognostic outcome in patients treated with tyrosine kinase inhibitors as first-line molecular-targeted therapy for metastatic renal cell carcinoma: Experience in real-world clinical practice in Japan, $\mathrm{Mol}$ Clin Oncol, 2015, 3, 601-606.

5) Escudier B, Eisen T, Stadler WM, Szczylik C, Oudard S, Siebels M, Negrier S, Chevreau C, Solska E, Desai AA, Rolland F, Demkow T, Hutson TE, Gore M, Freeman S, Schwartz B, Shan M, Simantov $\mathrm{R}$, Bukowski RM, Sorafenib in advanced clear-cell renal-cell carcinoma, $N$ Engl J Med, 2007, 356, 125134.

6) Motzer RJ, Hutson TE, Tomczak P, Michaelson MD, Bukowski RM, Oudard S, Negrier S, Szczylik C, Pili R, Bjarnason GA, Garcia-del-Muro X, Sosman JA, Solska E, Wilding G, Thompson JA, Kim ST, Chen I, Huang X, Figlin RA, Overall survival and updated results for sunitinib compared with interferon alfa in patients with metastatic renal cell carcinoma, J Clin Oncol, 2009, 27, 3584-3590.

7) Tomita Y, Shinohara N, Yuasa T, Fujimoto H, Niwakawa M, Mugiya S, Miki T, Uemura H, Nonomura N, Takahashi M, Hasegawa Y, Agata N, Houk B, Naito S, Akaza H, Overall survival and updated results from a phase II study of sunitinib in Japanese patients with metastatic renal cell carcinoma, Jpn J Clin Oncol, 2010, 40, 1166-1172.

8) Kondo T, Nakazawa H, Oya M, Kimura G, Fujii Y, Hatano T, Kawata N, Kume H, Morita M, Nakajima K, Ohno Y, Okegawa T, Takahashi S, Wakumoto Y, Horie S, Yamaguchi R, Saito K, Murakami M, Clinical efficacy and prognostic factors of tumor progression in Japanese patients with advanced renal cell carcinoma treated with sorafenib, Jpn J Clin Oncol, 2015, 45, 274-280.

9) Escudier B, Szczylik C, Hutson TE, Demkow T, Staehler M, Rolland F, Negrier S, Laferriere N, Scheuring UJ, Cella D, Shah S, Bukowski RM, Ran- domized phase II trial of first-line treatment with sorafenib versus interferon Alfa-2a in patients with metastatic renal cell carcinoma, J Clin Oncol, 2009, 27, 1280-1289.

10) Motzer RJ, Nosov D, Eisen T, Bondarenko I, Lesovoy V, Lipatov O, Tomczak P, Lyulko O, Alyasova A, Harza M, Kogan M, Alekseev BY, Sternberg CN, Szczylik C, Cella D, Ivanescu C, Krivoshik A, Strahs A, Esteves B, Berkenblit A, Hutson TE, Tivozanib Versus Sorafenib As Initial Targeted Therapy for Patients With Metastatic Renal Cell Carcinoma: Results From a Phase III Trial, J Clin Oncol, 2013, 31, 3791-3799.

11) Thomas EH, Vladimir L, Salman A, Viktor PS, Oleg NL, Angel HB, Brad R, Connie C, Sinil K, Nicholas $\mathrm{JV}$, Axitinib versus sorafenib as first-line therapy in patients with metastatic renal-cell carcinoma: a randomised open-label phase 3 trial, Lancet, 2013, 14, 1287-1294.

12) Devlin N, Parkin D, Does NICE have a cost-effectiveness threshold and what other factors influence its decisions? A binary choice analysis, Health Econ, 2004, 13, 437-452.

13) Weinstein M, How much are Americans willing to pay for a quality-adjusted life year? Med Care, 2008, 46, 343-345.

14) Shiroiwa $T$, Sung $Y$, Fukuda $T$, Lang H, Bae S, Tsutani K, International survey on willingness-topay (WTP) for one additional QALY gained: what is the threshold of cost effectiveness? Health Econ, 2010, 19, 422-437.

15) Ljungberg B, Bensalah K, Canfield S, Dabestani S, Hofmann F, Hora M, Kuczyk MA, Lam T, Marconi L, Merseburger AS, Mulders P, Powles T, Staehler M, Volpe A, Bex A, EAU guidelines on renal cell carcinoma, Eur Urol, 2015, 67, 913-924.

16) Stadler W, Figlin R, McDermott D, Dutcher J, Knox J, Miller W, Hainsworth J, Henderson C, George J, Hajdenberg J, Kindwall-Keller T, Ernstoff M, Drabkin H, Curti B, Chu L, Ryan C, Hotte S, Xia C, Cupit L, Bukowski R, Safety and efficacy results of the advanced renal cell carcinoma sorafenib expanded access program in North America, Cancer, 2010, 116, 1272-1280.

17) Choueiri T, Plantade A, Elson P, Negrier S, Ravaud A, Oudard S, Zhou M, Rini B, Bukowski R, Escudier B, Efficacy of sunitinib and sorafenib in metastatic papillary and chromophobe renal cell carcinoma, J Clin Oncol, 2008, 26, 127-131. 